\title{
Outcomes of surgical intervention for isolated active mitral valve endocarditis
}

Amir M. Sheikh, FRCS (C/Th), MBBS, Abdelsalam M. Elhenawy, MD, PhD, Manjula Maganti, MSc, Susan Armstrong, MSc, Tirone E. David, MD, and Christopher M. Feindel, MD

Objective: Although several studies have examined the outcomes of mitral valve repair for infective endocarditis, no studies have documented the long-term outcomes of surgical intervention for active endocarditis confined to the mitral valve.

\begin{abstract}
Methods: One hundred four patients underwent surgical intervention for active infective endocarditis confined to the mitral valve over a 27 -year period (mean age, $50 \pm 18$ years; $52 \%$ female). The infected valve was native in 81 patients, previously repaired 6 patients, and prosthetic in 17 patients. Staphylococcus aureus was the most commonly isolated (32\%) source of infection. Twenty-eight (27\%) patients had annular abscesses. Surgical intervention consisted of valve repair or replacement for limited infection and radical resection, annular patch reconstruction, and valve replacement for annular abscess. Mean follow-up was $5.6 \pm 4.4$ years (range, 0-20 years) and was complete.
\end{abstract}

Results: There were $9(8.7 \%)$ in-hospital deaths and $28(27 \%)$ late deaths. Overall survival at 5, 7, and 10 years was $73 \% \pm 5 \%, 68 \% \pm 5 \%$, and $58 \% \pm 6 \%$, respectively. At 7 years, freedom from recurrent endocarditis was $89 \% \pm 4 \%$ and freedom from reoperation was $94 \% \pm 3 \%$. Event-free survival at 7 and 10 years was $60 \% \pm 6 \%$ and $46 \% \pm 7 \%$, respectively, and was significantly higher in patients with native endocarditis versus those with nonnative endocarditis (ie, prosthetic or previously repaired; 7 years: $63 \% \pm 7 \%$ vs $50 \% \pm 12 \%, P<.005$ ). Preoperative shock, $S$ aureus infection, and bioprosthesis insertion were independent predictors of death from all causes. The patients in the bioprosthesis group were older ( $57 \pm 20$ years vs $44 \pm 15$ years in the mechanical group and $46 \pm 12$ years in the repair group, $P=.003$ ).

Conclusions: Surgical intervention for isolated active mitral valve endocarditis remains difficult, with high morbidity and mortality in the long term. Event-free survival is worse in those who have nonnative mitral valve endocarditis.

Infective endocarditis continues to carry high mortality and morbidity. No significant improvement has been seen in the past 2 decades. ${ }^{1}$ Early diagnosis followed by appropriate antibiotic therapy forms the cornerstone of treatment. ${ }^{2}$ Where medical management fails or complications of endocarditis ensue, timely surgical intervention is crucial for patient survival. Surgical intervention for endocarditis can be technically challenging because of the extensive tissue destruction and abscess formation that can arise, and reconstruction after radical debridement might be required.

Previously, we reported that in patients undergoing surgical intervention for endocarditis, mitral valve infection was seen in approximately two thirds of cases, half as isolated mitral involvement and half in conjunction with aortic involvement as double-valve endocarditis. ${ }^{3}$ Although several

From the Peter Munk Cardiac Centre, Toronto General Hospital, Toronto, Ontario, Canada.

Received for publication May 11, 2008; revisions received July 5, 2008; accepted for publication July 20, 2008.

Address for reprints: Christopher M. Feindel, MD, Antonio \& Helga DeGasperis Chair in Clinical Trials and Outcomes Research, 200 Elizabeth Street, 4N-480, Toronto General Hospital, Toronto, Ontario, M5G 2C4, Canada (E-mail: Chris.Feindel@ uhn.on.ca).

J Thorac Cardiovasc Surg 2009;137:110-6

$0022-5223 / \$ 36.00$

Copyright (c) 2009 by The American Association for Thoracic Surgery doi:10.1016/j.jtcvs.2008.07.033 studies have looked at outcomes after surgical intervention for infective endocarditis as a whole, ${ }^{4-6}$ studies focusing on mitral valve endocarditis have mainly examined the possible role of mitral valve repair. ${ }^{7-9}$ They have also been compounded by including patients with other infected or diseased valves who required concomitant operations. There have been no studies that have documented the long-term outcome of surgical intervention in patients who have active infective endocarditis that is confined to the mitral valve only.

\section{MATERIALS AND METHODS}

A review of the Toronto General Hospital cardiac surgery database revealed 104 patients who had undergone surgical intervention for active isolated mitral valve endocarditis from 1978 to 2004. Where necessary, relevant information was also derived by reviewing hospital medical records. Approval was obtained from the ethics review board of the hospital. Only patients with definite endocarditis were included, as evidenced by appropriate combinations of clinical features, operative findings, histopathology, and microbiology. Indications for surgical intervention were 1 or more of the following: shock $(n=15[14 \%])$, congestive cardiac failure $(n=60$ $[58 \%])$, cerebral embolism $(n=29[28 \%])$, and perivalvular abscess $(n=$ $28[27 \%]$ ). Table 1 shows the clinical characteristics of the patients. Our series included 2 intravenous drug abusers. There were no specific contraindications to surgical intervention, and each patient with endocarditis referred for surgical intervention was considered on a case-by-case basis. Surgical intervention was not offered only when it was deemed that it would not provide a substantial benefit in prognosis and quality of life. 


\section{Abbreviations and Acronyms \\ $\mathrm{CI}=$ confidence interval \\ $\mathrm{HR}=$ hazard ratio}

\section{Infecting Organisms}

Data for the infecting organism were available for 96 patients. Staphylococcus aureus was the most commonly encountered and present in 33 (32\%) patients; Streptococcus viridans was present in 23 (22\%) patients, Staphylococcus epidermidis was present in $9(9 \%)$ patients, Enterococcus faecalis was present in $1(1 \%)$ patient, other Streptococcus species were present in $11(11 \%)$ patients, other bacteria were present in $11(11 \%)$ patients, and culture-negative endocarditis was present in $8(8 \%)$ patients.

\section{Operative Procedures}

Our principles of surgical intervention for infective endocarditis consisted of uncompromising and thorough excision of all infected material and tissues, cutting back until healthy tissues were encountered. This was followed by appropriate reconstruction. Where infection was limited to the leaflets of the native valve or to the prosthetic valve, valve repair or simple replacement was performed. Valve repair was our preferred option, provided adequate valve tissue was left after complete excision of infected material. Where infection had extended to or beyond the annulus, as seen with abscess formation, surgical intervention consisted of radical resection of all infected tissue, followed by reconstruction as necessary with valve replacement, as has been previously described in detail. ${ }^{10-12}$ The choice of prosthesis was determined by means of informed consent of the patient in combination with the operating surgeon's judgment. Defects in the mitral annulus, ventricular muscle, or left atrial wall resulting from radical resection were patched with autologous or bovine pericardium.

Pre-existing mitral valve pathology was noted in 53 patients: myxomatous $(\mathrm{n}=33[33 \%])$, rheumatic $(\mathrm{n}=8[8 \%])$, prosthetic dysfunction $(\mathrm{n}=10[10 \%])$, and ischemic $(\mathrm{n}=2[2 \%])$. Operative data are summarized in Table 2. One patient very early in this series had prosthetic mitral valve endocarditis with a perivalvular leak 4 months after undergoing mitral valve replacement. Endocarditis was not apparent at the time of surgical intervention, and successful repair of the leak was undertaken. Patients in this series had no endocarditis involvement of any other valve and did not require any additional valve operations. Average cardiopulmonary bypass time was 93 \pm 38 minutes, with a crossclamp time of $69 \pm 30$ minutes.

All patients received intravenous antibiotics courses as per microbiology advice, usually continuing for 4 to 6 weeks after the operation. Once fully ambulatory and fit for discharge, patients had an in-dwelling intravenous catheter sited and were discharged home. A home care team of community nurses would visit the patient daily to administer the antibiotics as prescribed.

\section{Follow-up}

All patients were reviewed annually by the referring cardiologist, and data were collected prospectively. Our dedicated research personnel verified all cardiac events and maintained a comprehensive database. The mean follow-up was $5.6 \pm 4.35$ years (range, $0-20$ years) and was complete.

\section{Statistics}

Continuous variables were reported as mean values \pm standard deviation. All data analyses were performed with SAS 9.1 Software (SAS Institute, Cary, NC). Fisher's exact tests or $\chi^{2}$ tests were used to evaluate categorical variables univariately and were reported as frequencies. The Student $t$ test was used to analyze continuous variables that had normal distribution, and the Wilcoxon rank test was used for variables that had nonparametric distribution. The Kaplan-Meier method was used to calcu-
TABLE 1. Clinical characteristics

\begin{tabular}{|c|c|c|}
\hline Characteristic & No. & Percentage \\
\hline Age (y) & $50 \pm 18$ & \\
\hline Male sex & 50 & 48 \\
\hline \multicolumn{3}{|l|}{ Comorbid conditions } \\
\hline Diabetes mellitus & 13 & 13 \\
\hline Hypertension & 15 & 15 \\
\hline Chronic obstructive lung disease & 2 & 2 \\
\hline Renal failure & 7 & 7 \\
\hline Recent myocardial infarction $(<30 \mathrm{~d})$ & 3 & 3 \\
\hline Recent stroke or transient ischemic attack $(<30 \mathrm{~d})$ & 29 & 28 \\
\hline Peripheral vascular disease & 7 & 7 \\
\hline \multicolumn{3}{|l|}{ New York Heart Association class } \\
\hline I & 6 & 6 \\
\hline II & 2 & 2 \\
\hline III & 10 & 10 \\
\hline IV & 85 & 83 \\
\hline \multicolumn{3}{|l|}{ Preoperative rhythm } \\
\hline Sinus rhythm & 84 & 81 \\
\hline Atrial fibrillation & 20 & 19 \\
\hline Cardiogenic or septic shock & 15 & 14 \\
\hline Congestive cardiac failure & 60 & 58 \\
\hline \multicolumn{3}{|l|}{ Endocarditis } \\
\hline Native, never operated & 81 & 78 \\
\hline Previous repair & 6 & 6 \\
\hline Prosthetic & 17 & 16 \\
\hline Previous cardiac surgery & 26 & 25 \\
\hline CABG & 3 & 3 \\
\hline Aortic valve replacement & 2 & 2 \\
\hline Mitral valve repair & 6 & 6 \\
\hline Mitral valve replacement & 17 & 16 \\
\hline TV repair & 2 & 2 \\
\hline \multicolumn{3}{|l|}{ Left ventricular ejection fraction } \\
\hline$\geq 40 \%$ & 83 & 89 \\
\hline$<40 \%$ & 10 & 11 \\
\hline \multicolumn{3}{|l|}{ Timing of operation } \\
\hline Elective/same hospitalization & 45 & 51 \\
\hline Urgent/emergency & 43 & 49 \\
\hline
\end{tabular}

$C A B G$, Coronary artery bypass grafting; $T V$, tricuspid valve.

late estimates for long-term survival, freedom from reoperation, and event-free survival. Event-free survival was defined as the freedom from thromboembolism (including stroke), valve thrombosis, hemolysis, structural valve dysfunction, perivalvular leak, major bleeding event, endocarditis, reoperation, myocardial infarction, and death in hospital survivors. All preoperative variables with a univariate $P$ value of less than .25 or those judged to be clinically important were submitted to the multivariable model for Cox regression analysis to determine the independent predictors of operative and late deaths.

\section{RESULTS}

There were $9(8.7 \%)$ in-hospital deaths. Operative mortalities are summarized for the various subgroups in Table 3. Although cause of death was usually multifactorial, the main causes were multiorgan failure $(n=4)$, stroke $(n=$ $1)$, septicemia $(n=1)$, respiratory failure $(n=1)$, cardiac arrest $(\mathrm{n}=1)$, and retroperitoneal hemorrhage $(\mathrm{n}=1)$. Of the 
TABLE 2. Operative data

\begin{tabular}{lr}
\hline & No. \\
\hline Operation performed & 16 \\
Mitral valve repair & 1 \\
Mitral valve prosthesis repair & 87 \\
Mitral valve replacement & 23 \\
Mitral valve annulus reconstruction & 14 \\
Autologous pericardium & 9 \\
Bovine pericardium & \\
Chordal preservation in mitral valve replacement & 17 \\
Posterior only & 12 \\
Anterior and posterior & \\
Mitral valve prosthesis used & 43 \\
Mechanical & 44 \\
Bioprosthesis & 6 \\
Repair ring/band & 13 \\
Concomitant procedures & 2 \\
Coronary artery bypass grafting & 1 \\
Septal myectomy & \\
Replacement of ascending aorta & \\
\hline
\end{tabular}

significant factors identified in the univariate analysis for operative deaths, preoperative shock was present in 5 of these patients, preoperative renal failure was present in 4 patients, $S$ aureus infection was present in 7 patients, and preopera-

TABLE 3. Operative mortalities in various subgroups

\begin{tabular}{|c|c|c|c|}
\hline Variable & No. & Operative mortality (\%) & $P$ value \\
\hline Native endocarditis & 81 & 7.4 & \\
\hline Nonnative endocarditis & 23 & 13 & .41 \\
\hline Preoperative shock & 15 & 33.3 & .003 \\
\hline Preoperative renal failure & 7 & 57.1 & $<.001$ \\
\hline $\begin{array}{l}\text { Preoperative stroke, } \\
\text { transient ischemic } \\
\text { attack }\end{array}$ & 29 & 17.2 & .113 \\
\hline Paravalvular abscess & 28 & 10.7 & .699 \\
\hline $\begin{array}{l}\text { Staphylococcus aureus } \\
\text { infection }\end{array}$ & 33 & 21 & .004 \\
\hline Ejection fraction $<40 \%$ & 10 & 20 & .24 \\
\hline \multicolumn{4}{|l|}{ NHYA class } \\
\hline I/II/III & 18 & 0 & \\
\hline IV & 85 & 11 & .35 \\
\hline \multicolumn{4}{|l|}{ Timing of operation } \\
\hline $\begin{array}{l}\text { Elective/same } \\
\text { hospitalization }\end{array}$ & 45 & 0 & \\
\hline Urgent/emergency & 43 & 21 & $<.001$ \\
\hline $\begin{array}{l}\text { Preoperative atrial } \\
\text { fibrillation }\end{array}$ & 20 & 15 & .37 \\
\hline $\begin{array}{l}\text { Preoperative congestive } \\
\text { heart failure }\end{array}$ & 60 & 12 & .296 \\
\hline Preoperative syncope & 6 & 66.67 & $<.001$ \\
\hline Chordal preservation & 29 & 13.79 & .906 \\
\hline $\begin{array}{l}\text { MV annulus } \\
\text { reconstruction }\end{array}$ & 23 & 17.39 & .254 \\
\hline
\end{tabular}

TABLE 4. Postoperative complications

\begin{tabular}{lrcc}
\hline \multicolumn{1}{c}{ Complication } & No. & $\begin{array}{c}\text { Associated } \\
\text { mortality (\%) }\end{array}$ & $\boldsymbol{P}$ value \\
\hline Reopening for bleeding & 13 & 23 & .08 \\
Stroke & 4 & 50 & $<.05$ \\
$\quad$ Intraoperative & 3 & & \\
$\quad$ Postoperative & 1 & & \\
Sternal wound infection (deep) & 2 & 50 & .17 \\
Renal failure & 4 & 75 & $<.05$ \\
Sepsis & 6 & 50 & $<.01$ \\
Pulmonary complications & 31 & 19 & $<.05$ \\
Insertion of permanent pacemaker & 12 & 8.3 & 1.0 \\
\hline
\end{tabular}

tive syncope was present in 4 patients, and the operation was performed on an urgent or emergency basis in all. Three patients had prosthetic endocarditis. When examining for operative mortality by surgical era, we found no difference between the first and second halves of the study period (1978-1994: $10.3 \%$ vs $1995-2004: 7.7 \%, P=.73$ ).

Mean stay in the intensive care unit was $7 \pm 20.8$ days (median, 2 days), with a mean ventilation time of $5.4 \pm$ 20.3 days (median, 13 hours). Postoperative complications are summarized in Table 4. Mean hospital stay was $17 \pm$ 17 days (median, 12 days).

A further 28 patients died during follow-up. There were 9 valve-related deaths (recurrent endocarditis in 6, perivalvular leak in 1, and stroke in 2) and a further 6 cardiac deaths (myocardial infarction in 1, congestive heart failure in 2, cardiomyopathy in 1, and sudden death in 2). There were 13 noncardiac deaths (cancer in 4, gastrointestinal hemorrhage unrelated to anticoagulation in 1 , hepatitis in 1 , renal failure in 2, pneumonia in 2, pulmonary embolism in 1, diabetes in 1 , and suicide in 1). Survival was $73 \% \pm 5 \%, 68 \% \pm 5 \%$, and $58 \% \pm 6 \%$ at 5,7 , and 10 years, respectively (Figure 1 ). Survival was similar in those undergoing surgical intervention for native mitral valve endocarditis than among those with nonnative (ie, prosthetic or previously repaired) mitral valve endocarditis (7-year survival: $70 \% \pm 6 \%$ vs $62 \% \pm$

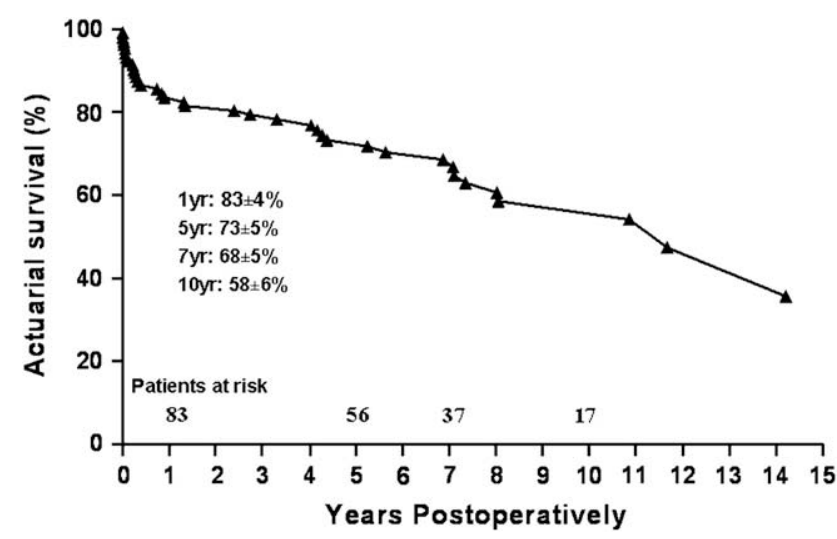

FIGURE 1. Long-term actuarial survival for all patients. 


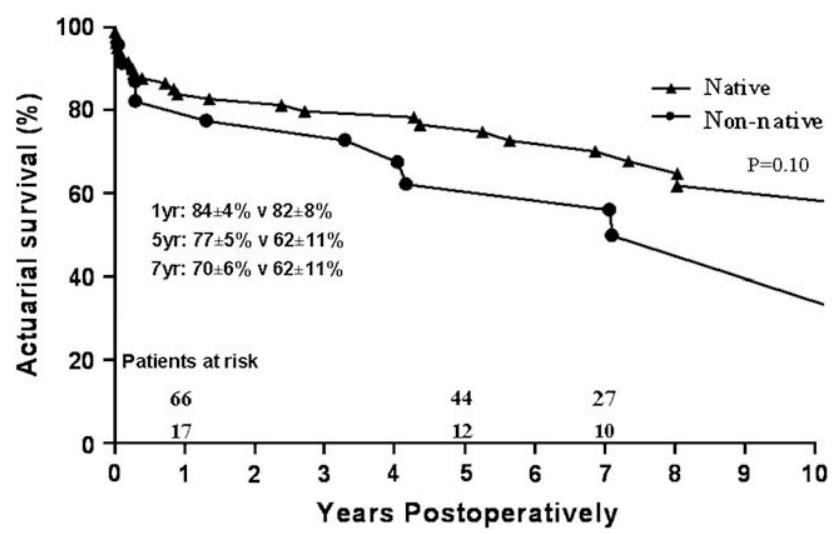

FIGURE 2. Long-term actuarial survival for the native versus nonnative groups.

$11 \%$, respectively; $P=.10$; Figure 2 ). Cox regression analysis identified shock (hazard ratio [HR], 8.87; 95\% confidence interval $[\mathrm{CI}], 3.1-25.2 ; P<.0001), S$ aureus infection (HR, 3.87; 95\% CI, 1.7-8.8; $P=.001)$, and tissue mitral valve prosthesis (HR, 7.22; 95\% CI, 2.7-19.6; $P=$ .0001 ) as independent predictors of death from all causes. Increasing age was not a predictor of death in the model, even when forced. Further comparison of the bioprosthesis group with the mechanical and mitral repair groups found age to be the only significant difference in clinical, operative, and postoperative characteristics between the groups. Mean age in the bioprosthesis group was $57 \pm 20$ years versus 44 \pm 15 years in the mechanical replacement group and $46 \pm$ 12 years in the repair group $(P=.003)$. We were able to ascertain septic shock $(\mathrm{n}=6)$ versus cardiogenic shock $(\mathrm{n}=$ 6) in 12 of 15 patients who presented with preoperative shock. When the Cox model was recalculated with this additional information, no significant difference was found between septic and cardiogenic shock.

Recurrence of endocarditis was seen in 9 patients. All had undergone mitral valve replacement ( 6 with a bioprosthesis and 3 with a bileaflet mechanical prosthesis). Five had had an abscess originally. Of the significant factors associated with operative and late deaths, preoperative shock was present in 2, syncope was present in 1, $S$ aureus infection was present in 5, and urgent/emergency timing was present in 4 . Four had early endocarditis ( $\leq 1$ year). The infecting organism was the same as the original episode in 4 patients and different in 2 , and in 3 patients this information was missing because the patients were readmitted to other hospitals. Two of these patients underwent reoperation and survived. Of the 7 patients managed conservatively with antibiotic therapy, there was only 1 survivor, a young female patient with prosthetic mitral valve endocarditis with a small vegetation who was clinically well and responded very well to antibiotic therapy with successful resolution of the endocarditis. Of the 6 endocarditis-related deaths, 1 had recurrence 8 years later affecting the native aortic valve,
TABLE 5. Late morbidity

\begin{tabular}{lc}
\hline \multicolumn{1}{c}{ Late complication } & No. (with consequent death) \\
\hline Endocarditis recurrence & $9(6)$ \\
Thromboembolic stroke & $7(2)$ \\
Reoperations & $11(0)$ \\
$\quad$ Bioprosthetic structural valve & 7 \\
$\quad$ deterioration & \\
Recurrent endocarditis & 2 \\
Perivalvular leak & 1 \\
Failure of repair & 1 \\
Perivalvular leak & $2(0)$ \\
Major anticoagulation-related hemorrhage & $1(0)$ \\
\hline
\end{tabular}

whereas the mitral valve prosthesis was unaffected, and another was an intravenous drug abuser. Freedom from recurrent endocarditis overall was $89 \% \pm 4 \%$ at 7 years and $86 \%$ $\pm 5 \%$ at 10 years. Seven-year freedom from endocarditis was $91 \% \pm 4 \%$ for native valve endocarditic and $83 \% \pm$ $9 \%$ for nonnative mitral valve endocarditis $(P=.36)$.

Late morbidity events are summarized in Table 5. There were no instances of valve thrombosis or hemolysis. There were 11 reoperations. There were no operative mortalities for patients undergoing reoperation, and all are alive at the latest follow-up. Freedom from reoperation was $94 \% \pm$ $3 \%$ at 7 years and $84 \% \pm 6 \%$ at 10 years (Figure 3). Freedom from reoperation was greater in the native group compared with that in the nonnative endocarditis group, although this did not reach statistical significance (7-year freedom: $96 \% \pm 3 \%$ and $89 \% \pm 8 \%$, respectively; $P=$ $.085)$.

At latest follow-up, 67 patients were alive, of whom 56 were also free from reoperation and were in New York Heart Association functional class I $(n=39[69.6 \%])$, II $(n=11$ $[19.6 \%])$, or III $(n=6[10.7 \%])$. Overall event-free survival at 7 and 10 years was $60 \% \pm 6 \%$ and $46 \% \pm 7 \%$, respectively (Figure 4 ) and was significantly higher in the native mitral valve endocarditis group compared with that in the nonnative group $(63 \% \pm 7 \%$ vs $50 \% \pm 12 \%, P<.005$;

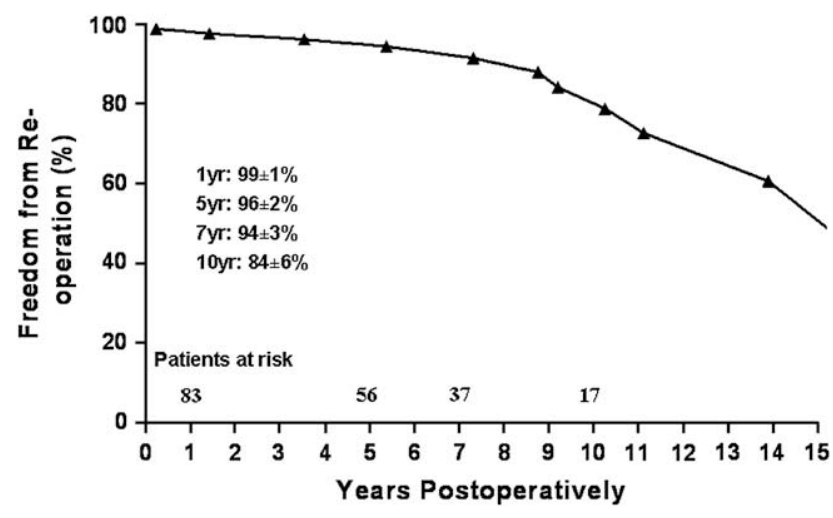

FIGURE 3. Long-term freedom from reoperation for all patients. 


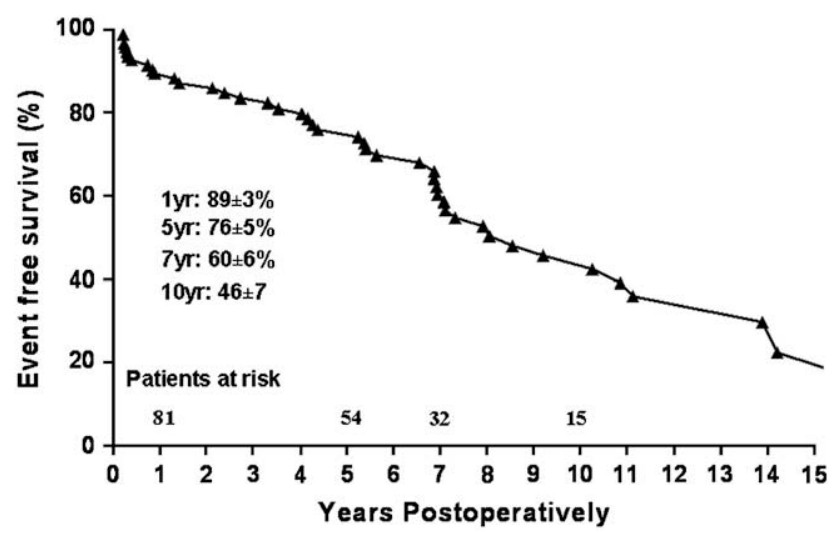

FIGURE 4. Event-free survival for all patients.

Figure 5). The benefit in the native endocarditis group was primarily a consequence of reduced valve-related morbidity and mortality (7-year freedom from valve-related mortality and morbidity: $76 \% \pm 7 \%$ vs $61 \% \pm 13$, respectively; $P=.02$ ).

In making a comparison of outcomes of patients undergoing mitral repair with those undergoing replacement, we examined the subgroup comprising patients whose mitral valve was truly native (ie, unoperated; $\mathrm{n}=81$ ) or had undergone previous repair $(n=6)$. Those with prior mitral replacement were excluded because repair was obviously not a surgical option for them. Sixteen of these patients underwent repair, and 71 underwent replacement. There was no significant survival difference in those who underwent mitral valve repair compared with those receiving mitral valve replacement (5-year survival: $88 \% \pm 8 \%$ vs $75 \% \pm 5 \%$, respectively; $P=.19$ ). There was no difference between groups for freedom from recurrent endocarditis or for freedom from reoperation. Event-free survival was improved in the mitral repair group, but this did not achieve statistical significance (5-year eventfree survival: $91 \% \pm 9 \%$ vs $78 \% \pm 5 \%, P=.25$ ).

\section{DISCUSSION}

We have presented the early and late outcomes of surgical intervention for active infective endocarditis confined to the mitral valve in a cohort of patients over a 27 -year period. Mitral valve endocarditis carries significant mortality in the short term (almost 9\% in our series) and also in the longer term, with a $42 \%$ mortality at 10 years. Postoperative recovery is protracted; in our series mean intensive care unit stay was 7 days, with a mean hospital stay of 17 days, and complications were common. One third of late deaths were valve related, and the incidence of recurrent endocarditis was almost $10 \%$ in hospital survivors.

There have been a number of studies that have examined surgical outcomes after infective endocarditis. ${ }^{3-6}$ We published our own series of 383 patients over a 27 -year period, in which all cases of patients with active infective endocarditis undergoing surgical intervention were reviewed. ${ }^{3}$ Sur-

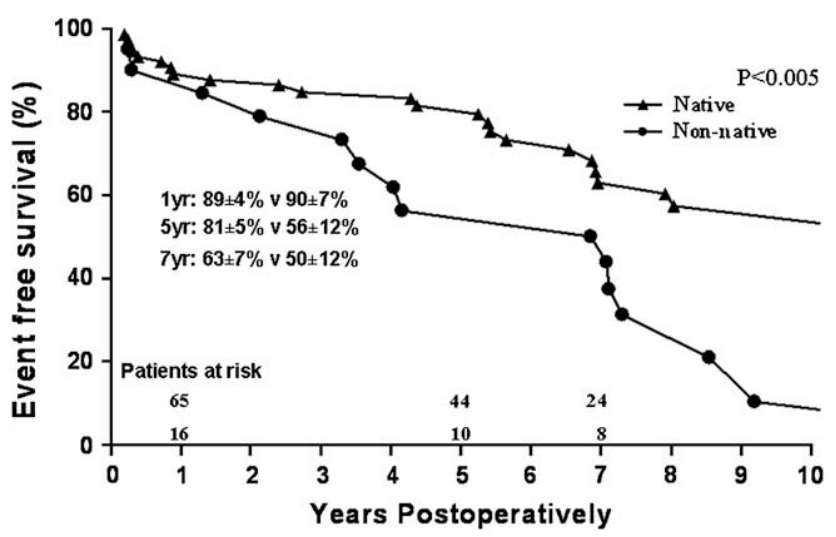

FIGURE 5. Event-free survival for the native versus nonnative groups.

gical intervention for aortic valve endocarditis was most frequent, followed by both mitral valve and double-valve (aortic and mitral) endocarditis. There have, to date, been no reports on the long-term outcomes of patients undergoing surgical intervention for isolated and active mitral valve endocarditis. Our current series is a subset of our original group of 383 patients.

Gammie and coworkers ${ }^{4}$ reviewed short-term outcomes for patients who underwent surgical intervention for native mitral valve endocarditis. The authors identified 6627 patients from the Society of Thoracic Surgeons National Cardiac Database during a 10 -year period. Active endocarditis was present in $40 \%$ of their series. Overall operative mortality was $8.7 \%$ and was higher in the active endocarditis group ( $15 \%$ vs $4 \%$ in the treated group). Our series consisting solely of patients with active endocarditis carried an operative mortality of $8.7 \%$. In Gammie and coworkers' series, although patients with concomitant aortic valve involvement were excluded, those requiring tricuspid repair were included, but the number for this was not given. Patients with active endocarditis were more likely to have comorbidities (renal failure, stroke, and diabetes), more likely to have emergency/salvage operations, and less likely to undergo repair ( $16 \%$ vs $41 \%$ for the treated group). The replacement group had a higher operative mortality ( $10.8 \%$ vs $3.7 \%$ for the repair group) but also had a higher incidence of comorbidities (preoperative renal failure, stroke, congestive heart failure, and diabetes). Active endocarditis, stroke within 2 weeks of surgical intervention, and mitral valve replacement were independent predictors of operative mortality on multivariable regression analysis. In our series the number of operative deaths $(n=9)$ was insufficient to allow multivariable analysis. However, univariate analysis revealed that preoperative shock, renal failure, syncope, $S$ aureus infection, and urgent/emergency operation were associated with increased risk of operative death.

Patients with active endocarditis tend to be sicker than those undergoing surgical intervention for healed 
endocarditis. Furthermore, greater tissue destruction is likely to be encountered in active cases, prompting the need for an early operation. This makes surgical risk greater in patients with active endocarditis and also makes feasibility of repair less likely.

Studies on mitral valve endocarditis have mainly focused on the role of mitral valve repair and have included both cases of healed and active endocarditis, as well as endocarditis involving other valves. Muehrcke and associoates ${ }^{8}$ from the Cleveland Clinic reviewed 146 patients undergoing surgical intervention for native mitral valve endocarditis, of whom $40 \%$ had active infection and $60 \%$ were healed. Thirty percent of their patients had endocarditis involving other valves in addition to the mitral valve, and these required concomitant operations. Iung and colleagues ${ }^{7}$ reported on 63 patients who underwent mitral valve repair for native mitral valve endocarditis, $40 \%$ of whom had active infection. Concomitant aortic valve endocarditis requiring replacement was seen in $11(17 \%)$ patients, and 1 required tricuspid valve repair for endocarditis. Five-year survival and event-free survival was $96 \%$ and $62 \%$, respectively, for the active endocarditis group.

Ruttmann and coworkers ${ }^{9}$ reviewed 68 patients who underwent surgical intervention for active mitral valve endocarditis. There was no difference in 5-year actuarial survival between valve repair and replacement $(85 \%$ vs $67 \%$ ), although-event free survival at 5 years was significantly higher in the repair group ( $80 \%$ vs $55 \%$ ). Multivariable analysis demonstrated replacement and impaired left ventricular function to be significant adverse independent predictors of event-free survival. However, their patient population also did not consist of isolated mitral valve endocarditis. Infective involvement of the aortic valves, tricuspid valves, or both required concomitant aortic valve replacement in 12 cases, with an additional 4 tricuspid valve procedures. In our study mitral valve repair was associated with higher event-free survival (5-year survival: $91 \% \pm 9 \%$ vs $78 \% \pm 5 \%, P=.25$ ), although this was not statistically significant and there was no difference in actuarial survival (5year survival: $88 \% \pm 8 \%$ vs $75 \% \pm 5 \%, P=.19)$. These findings should be interpreted cautiously because the number of mitral valve repairs totaled 16 .

It is well established that prosthetic valve endocarditis carries a worse outcome than native valve endocarditis. ${ }^{3,13,14}$ Studies on native mitral valve endocarditis have often included cases of infection involving the previously repaired mitral valve. ${ }^{4,7-9}$ However, a prosthesis, such as a mitral valve ring, might be present as part of the previous repair. The investigators of a large multicenter database on endocarditis classed infected mitral rings as prosthetic valve endocarditis. ${ }^{14}$ Even in the absence of a prosthesis, because the mitral valve has previously undergone surgical intervention, we would suggest that such valves are more appropriately classified with prosthetic valve patients in a group termed "nonnative." Our comparison of survival outcomes for endocarditis of the native and therefore unoperated mitral valve with the nonnative mitral valve (ie, previously operated, whether repaired or replaced) revealed event-free survival to be significantly improved in the native group. Event-free survival at 7 years was almost $25 \%$ greater in the native endocarditis group. Freedom from reoperation and overall survival were higher in the native group, although these differences did not achieve statistical significance. The nonnative group had a greater incidence of abscess formation $(43 \%$ vs $22 \%, P=.04)$, preoperative atrial fibrillation $(52 \%$ vs $10 \%, P<.0001)$, and prior coronary artery bypass $(13 \%$ vs $0 \%, P<.01)$ or aortic valve surgery $(9 \%$ vs $0 \%, P=.047)$.

The presence of preoperative shock and $S$ aureus infection as predictors of death from all causes is not surprising and has been reported before. ${ }^{3,14,15}$ Hill and colleagues ${ }^{16}$ identified septic shock as an independent predictor of mortality at 6 months in 95 patients undergoing surgical intervention for definite endocarditis. In our study we did not find type of shock (septic or cardiogenic) to be predictive of death from all causes in the Cox regression analysis, but our individual numbers available for this were small ( $n=6$ vs 6 ). Use of a tissue mitral valve prosthesis as a predictor of death was most likely related to these patients being older than those who underwent mechanical valve insertion or mitral valve repair. Although age did not emerge as an independent predictor of death, analysis of patient characteristics for the individual operative groups of repair or mechanical or tissue prosthesis insertion revealed age as the only significant difference between the groups. The mean age of patients receiving a bioprosthesis was $56.5 \pm 19.7$ years, with those receiving a mechanical valve being 44.4 \pm 15.2 years of age and those undergoing repair being $45.5 \pm 12.4$ years of age ( $P=.003$, analysis of variance).

The Stanford group specifically addressed the effect of valve choice in left-sided infective endocarditis in an analysis of 306 patients over a 32-year period. ${ }^{17}$ Isolated aortic valve replacement was most common $(62 \%)$, followed by isolated mitral valve replacement (29\%). Almost one third of patients in their series had healed endocarditis. No significant difference was found in either operative deaths or late survival when comparing tissue and mechanical prostheses at 10 and 20 years. Increased age and prosthetic endocarditis, among other factors, were independent predictors of operative and late death by means of multivariable analysis. Freedom from recurrent endocarditis and late reoperation were not statistically different between the bioprosthesis and mechanical groups. Choice of valve prosthesis did not emerge as an independent predictor of death for either the operative period or for late survival. In our current study we suspect that bioprosthesis use as a predictor of late death is emerging perhaps as a surrogate for increased age. 
Surgical management of paravalvular abscess can be technically challenging. In our series of 383 consecutive endocarditis patients, ${ }^{3}$ paravalvular abscess was an independent predictor of operative mortality. We have subsequently described the outcomes of surgical intervention for endocarditis (of any valve) complicated by paravalvular abscess in 135 patients. ${ }^{18}$ High operative mortality $(15.5 \%)$ was found. Ten-year overall survival was $57 \%$, which is, in fact, similar to that of our current study $(58 \% \pm 6 \%)$. In the present series mitral paravalvular abscess was present in $28(27 \%)$ patients and was associated with $10.7 \%$ operative mortality. It did not emerge as an independent predictor of late death. The relatively small number of hospital deaths precluded meaningful regression analysis to examine this. In addition, it is possible that the relatively small number of patients with a mitral annular abscess underestimates its prognostic effect on operative, as well as late, death.

Although operative mortality was significant $(8.7 \%)$, long-term actuarial survival $(58 \% \pm 6 \%)$ was favorable when compared with that seen in other series of mitral valve surgery. The Edinburgh Heart Valve Trial, ${ }^{19}$ one of the largest randomized trials comparing mechanical with porcine bioprostheses, reported 10-year actuarial survival of $53 \%$ and $47 \%$ for mechanical and tissue prostheses, respectively, in the subgroup of patients who had isolated mitral valve replacement. Comparable results were reported from the US Department of Veteran's Administration Heart Valve trial. ${ }^{20}$

In summary, we have presented early and late outcomes of surgical intervention for active endocarditis that is confined to the mitral valve. For a difficult and challenging condition, satisfactory operative and long-term survival can be achieved. Good long-term freedom from recurrent endocarditis and repeat operation are possible. Event-free survival is impaired in those undergoing surgical intervention for nonnative mitral valve endocarditis.

\section{References}

1. Moreillon P, Que YA. Infective endocarditis. Lancet. 2004;363:139-49.

2. Mylonakis E, Calderwood SB. Infective endocarditis in adults. $N$ Engl J Med. 2001;345:1318-30.
3. David TE, Gavra G, Feindel CM, Regesta T, Armstrong S, Maganti MD. Surgical treatment of active infective endocarditis: a continued challenge. J Thorac Cardiovasc Surg. 2007;133:144-9.

4. Gammie JS, O’Brien SM, Griffith BP, Peterson ED. Surgical treatment of mitral valve endocarditis in North America. Ann Thorac Surg. 2005;80:2199-204.

5. Gillinov AM, Diaz R, Blackstone EH, Pettersson GB, Sabik JF, Lytle BW, et al. Double valve endocarditis. Ann Thorac Surg. 2001;71:1874-9.

6. Kaiser SP, Melby SJ, Zierer A, Schuessler RB, Moon MR, Moazami N, et al. Long-term outcomes in valve replacement surgery for infective endocarditis. Ann Thorac Surg. 2007;83:30-5.

7. Iung B, Rousseau-Paziaud J, Cormier B, Garbarz E, Fondard O, Brochet E, et al. Contemporary results of mitral valve repair for infective endocarditis. $J$ Am Coll Cardiol. 2004;43:386-92.

8. Muehrcke DD, Cosgrove DM III, Lytle BW, Taylor PC, Burgar AM, Durnwald $\mathrm{CP}$, et al. Is there an advantage to repairing infected mitral valves? Ann Thorac Surg. 1997;63:1718-24.

9. Ruttmann E, Legit C, Poelzl G, Mueller S, Chevtchik O, Cottogni M, et al. Mitral valve repair provides improved outcome over replacement in active infective endocarditis. J Thorac Cardiovasc Surg. 2005;130:765-71.

10. d'Udekem Y, David TE, Feindel CM, Armstrong S, Sun Z. Long-term results of surgery for active infective endocarditis. Eur J Cardiothorac Surg. 1997;11: 46-52.

11. David TE, Komeda M, Brofman PR. Surgical treatment of aortic root abscess. Circulation. 1989;80:I269-74.

12. David TE, Feindel CM, Armstrong S, Sun Z. Reconstruction of the mitral anulus. A ten-year experience. J Thorac Cardiovasc Surg. 1995;110:1323-32.

13. Wang A, Pappas P, Anstrom KJ, Abrutyn E, Fowler VG Jr, Hoen B, et al. The use and effect of surgical therapy for prosthetic valve infective endocarditis: a propensity analysis of a multicenter, international cohort. Am Heart J. 2005;150: 1086-91.

14. Wang A, Athan E, Pappas PA, Fowler VG Jr, Olaison L, Pare C, et al. Contemporary clinical profile and outcome of prosthetic valve endocarditis. JAMA. 2007; 297:1354-61.

15. Miro JM, Anguera I, Cabell CH, Chen AY, Stafford JA, Corey GR, et al. Staphylococcus aureus native valve infective endocarditis: report of 566 episodes from the International Collaboration on Endocarditis Merged Database. Clin Infect Dis. 2005;41:507-14.

16. Hill EE, Herregods MC, Vanderschueren S, Claus P, Peetermans WE, Herijgers P. Outcome of patients requiring valve surgery during active infective endocarditis. Ann Thorac Surg. 2008;85:1564-9.

17. Moon MR, Miller DC, Moore KA, Oyer PE, Mitchell RS, Robbins RC, et al. Treatment of endocarditis with valve replacement: the question of tissue versus mechanical prosthesis. Ann Thorac Surg. 2001;71:1164-71.

18. David TE, Regesta T, Gavra G, Armstrong S, Maganti MD. Surgical treatment of paravalvular abscess: long-term results. Eur J Cardiothorac Surg. 2007;31:43-8.

19. Hammermeister K, Sethi GK, Henderson WG, Grover FL, Oprian C, Rahimtoola SH. Outcomes 15 years after valve replacement with a mechanical versus a bioprosthetic valve: final report of the Veterans Affairs randomized trial. J Am Coll Cardiol. 2000;36:1152-8.

20. Oxenham H, Bloomfield P, Wheatley DJ, Lee RJ, Cunningham J, Prescott RJ, et al. Twenty year comparison of a Bjork-Shiley mechanical heart valve with porcine bioprostheses. Heart. 2003;89:715-21. 